\title{
Reach- and catchment-scale determinants of the distribution of freshwater mussels (Bivalvia: Unionidae) in south-eastern Michigan, U.S.A.
}

\author{
S. E. MCRAE, ${ }^{*}{ }^{\dagger}$ J. D. ALLAN ${ }^{\dagger}$ AND J. B. BURCH ${ }^{\ddagger}$ \\ *North Carolina Natural Heritage Program, Raleigh, NC, U.S.A. \\ †School of Natural Resources and Environment, University of Michigan, Ann Arbor, MI, U.S.A. \\ $\ddagger$ Mollusk Division, University of Michigan Museum of Zoology, Ann Arbor, MI, U.S.A.
}

\begin{abstract}
SUMMARY
1. We investigated the diversity and distribution of freshwater mussels at 40 sites in an agricultural catchment, the River Raisin in south-eastern Michigan, to relate mussel assemblages and individual taxa to reach and catchment-scale variables. Unionids were surveyed by timed searches in 100-m reaches, and in-stream and riparian habitat were quantified as well as flow, water chemistry and channel morphology. Land use/cover and surficial geology were determined for site subcatchments and riparian buffers.

2. Some 21 mussel species were found overall; richness ranged from 0 to 12 living species per site. From the upper to middle to lower catchment, the number of individuals, number of species, Shannon-Weaver diversity and relative abundance of intolerant unionids all declined significantly.

3. Four groupings based on overall mussel diversity and abundance were significantly related to reach-scale habitat variables. The richest mussel assemblages were associated with sites with higher overall habitat quality, greater flow stability, less fine substratum, and lower specific conductance.

4. Stepwise multiple regressions revealed that the distribution and abundance of the total mussel assemblage, as well as the most common species, could be predicted from a combination of reach- and catchment-scale variables $\left(R^{2}=0.63\right.$ for total mussels, $R^{2}=0.51-0.86$ for individual species).

5. Flow stability, substratum composition and overall reach habitat quality were the most commonly identified reach-scale variables, and measures of surficial geology were the most effective catchment-scale variables. The spatial pattern of geology is likely to be responsible for the diversity gradient from the upper to the lower catchment.

6. Prior studies, attempting to explain mussel distributions from local habitat features alone, have found relatively weak relationships. By employing a combination of reach- and catchment-scale habitat variables, this study was able to account for a substantial amount of the spatial variability in mussel distributions.
\end{abstract}

Keywords: catchment, freshwater mussels, habitat, land-use, Unionidae

Correspondence: Sarah McRae, North Carolina Natural Heritage

Program, MSC 1601, Raleigh, NC 27699-1601, U.S.A.

E-mail: sarah.mcrae@ncmail.net

\section{Introduction}

Zoogeographic factors exert strong controls over the broad-scale distribution of freshwater mussels (van der Schalie, 1945; van der Schalie \& van der Schalie, 1950; Strayer, 1993), and gross organic or toxic pollution can eliminate populations from otherwise 
suitable habitat (Stansbery, 1970; Fuller, 1974; McMahon, 1991). However, the influence of other ecological factors on the distribution of unionids is less clear. Some studies have found that microhabitat measures, such as local current velocity and substratum, determine the suitability of habitat for freshwater mussels (van der Schalie, 1938; Strayer, 1993; Vaughn, 1997). Others (Tevesz \& McCall, 1979; Strayer, 1981; Holland-Bartels, 1990; Layzer \& Madison, 1995) have shown that the properties of the microhabitat only poorly predict the occurrence and species composition of freshwater bivalves in running waters. However, Strayer $(1983,1993)$ found that macrohabitat descriptors, especially stream size, could predict the broad-scale distribution of freshwater mussels. Thus, studies examining habitat across large spatial scales might be more useful than a traditional microhabitat approach for determining the distribution of freshwater mussels in streams (Strayer \& Ralley, 1993).

While catchment versus local-scale influences on fish and macroinvertebrates have received considerable attention (Schlosser, 1991; Richards, Johnson \& Host, 1996; Roth, Allan \& Erickson, 1996; Allan, Erickson \& Fay, 1997; Wang et al., 1997; Harding et al., 1998; Wang et al., 2001), few such investigations have been undertaken with freshwater mussels. However, Strayer (1983); Vaughn (1997) and Arbuckle \& Downing (2002) have shown that regional factors such as land use and geology strongly affect mussel communities. Land use can influence the discharge regime, the water velocity experienced by benthic organisms and sediment supply, all factors likely to affect mussels. Siltation interferes with their filtration, and mussels are susceptible to desiccation and exposure to mammalian predation during extreme low flows, and to scouring of the substratum by high flows (McMahon, 1991; Strayer, 1993; Di Maio \& Corkum, 1995). Some of these influences may be observable as reach-scale habitat changes, and some may best be detected at the catchment level as a function of land use and underlying geology.

We hypothesised that unionids are influenced by a combination of reach-scale habitat variables and subcatchment-scale geology and land use variables. We examined this hypothesis in the River Raisin of south-eastern Michigan, an agricultural catchment where mussel distribution has been studied previously (Strayer, 1983). Our objectives were to: (i) determine the relative abundance of unionid species throughout the catchment; (ii) relate the occurrence of mussels to substratum, water chemistry, flow, channel shape and additional within-reach habitat variables and (iii) examine the relationship of mussels to larger-scale variables, including surficial geology and land use. In particular, we wished to explore the relative importance of reach-scale habitat variables versus subcatchment-scale geology and land-use variables as predictors of the richness of mussel assemblages and the distribution of individual species.

\section{Methods}

\section{Study area}

The River Raisin in south-eastern Michigan (Fig. 1) flows into western Lake Erie and drains an area of approximately $2780 \mathrm{~km}^{2}$ (Smith, Taylor \& Grimshaw, 1981; Roth et al., 1996). The upper basin is moderately undulating, consisting of moraines, till and outwash plains, with flat land in the lower basin, underlain by sands and clays from glacial Lake Erie (Knutilla \& Allen, 1975). The upper basin is part of the Eastern Corn Belt Ecoregion, whereas the lower basin falls within the Huron-Erie Lake Plain Ecoregion (Omernik, 1987). Land use/cover also varies throughout the catchment (Allan et al., 1997). In the hilly upper catchment, wetlands and small lakes are abundant, the riparian zone is mostly forested, and farming is limited. The middle region of the basin has more agricultural land and less forest and wetland than the upper catchment. The lower region of the catchment, where the river meanders extensively, is marked by a sharp transition from glacial to lake plain geology and large tracts of corn and soybeans dominate the lower catchment (Cifaldi et al., in press).

Sites were selected to represent the range of conditions along the mainstem of the Raisin, and also to sample tributaries representing a range of reachscale habitat and surrounding land uses. In addition, locations with historical records were included. A total of 40 sites were sampled during 2000 and 2001: nine sites in the upper catchment, including two tributaries; twelve sites in the middle region, including five tributaries; and nineteen sites in the lower catchment, including six tributaries (Fig. 1). 
(a)
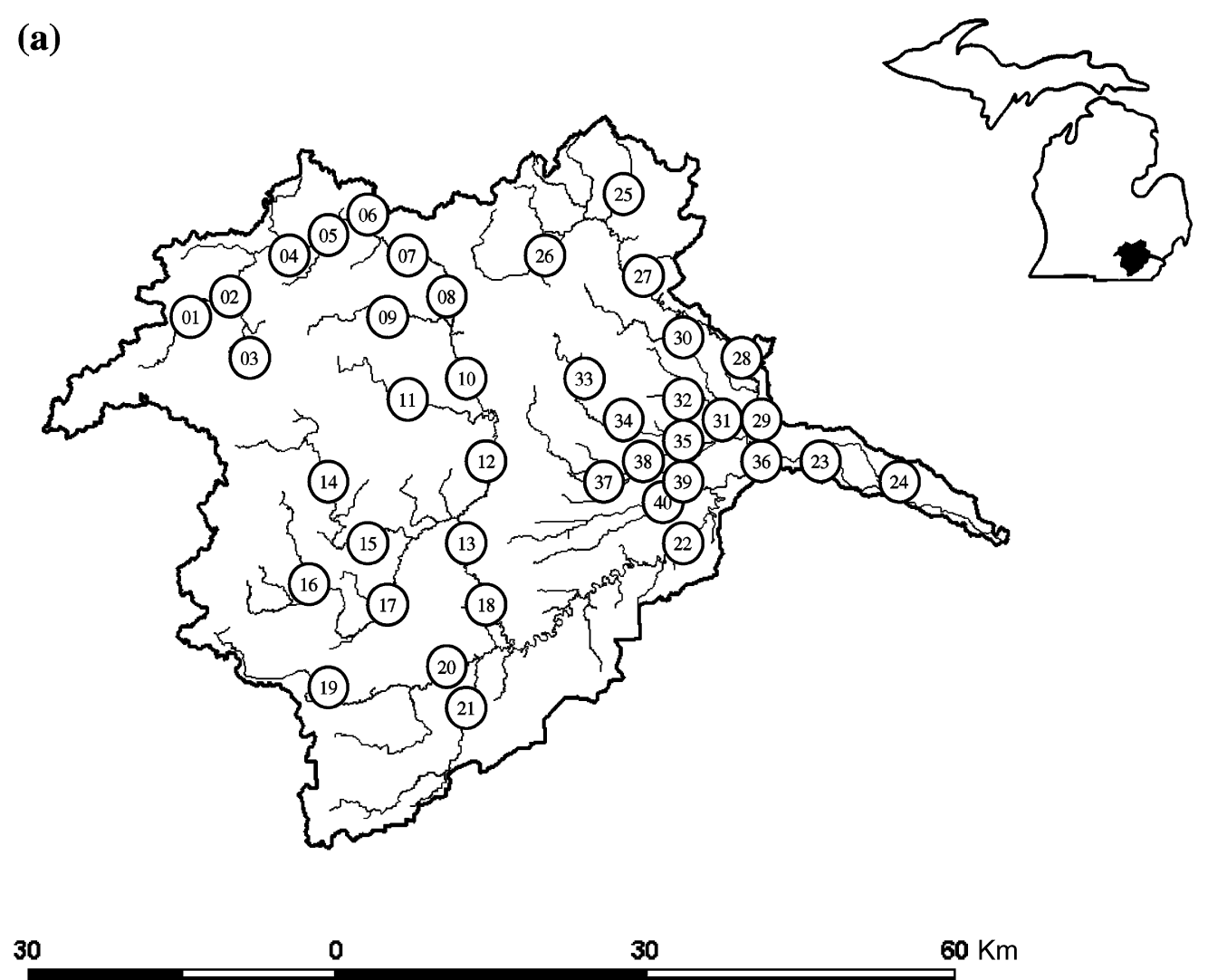

(b)

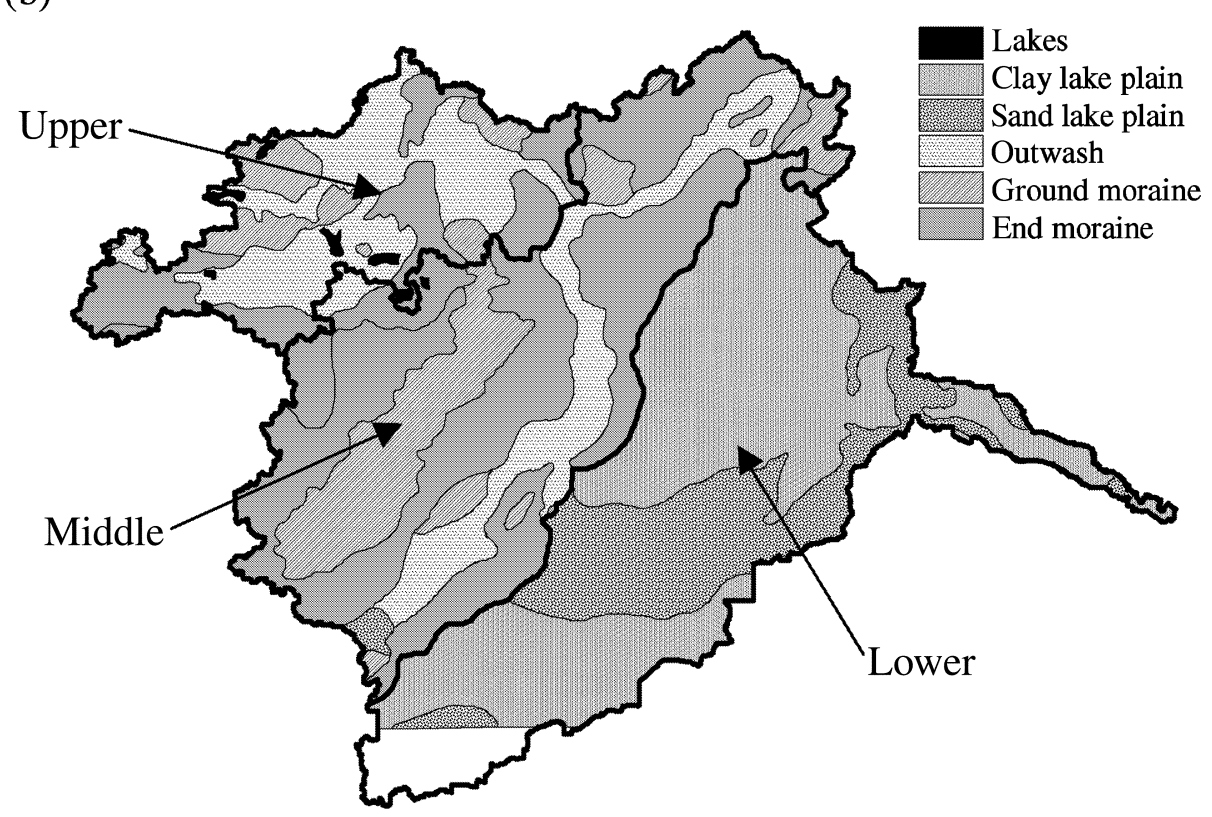

Fig. 1 The River Raisin catchment in southeastern Michigan, showing (a) the location of the 40 sites sampled, and (b) the catchment's surficial geology and the delineation of upper, middle and lower regions. Nine sites were located in the upper basin, twelve sites in the middle basin, and nineteen sites in the lower basin. 


\section{Mussel surveys}

We used a semi-quantitative, timed-search approach to determine species composition and relative abundance of mussel assemblages. Timed searches allow a more complete assessment of mussel communities than substratum excavation methods and are more likely to locate rare species (Kovalak, Dennis \& Bates, 1986; Strayer, Claypool \& Sprague, 1997; Goforth et al., 2001). Mussel nomenclature followed Turgeon et al. (1998), except in the case of the taxonomic uncertainty surrounding Lampsilis ovata (=cardium) and Pyganodon (=Anodonta) grandis, which are referred to in this paper as Lampsilis cardium (Rafinesque) and Pyganodon grandis (Say), respectively.

A $100-\mathrm{m}$ reach was delineated at each site and timed searches for mussels using glass-bottom aquascopes were performed at $10-\mathrm{m}$ intervals. The entire riverbed was examined within each 10-m interval, and mussels were placed in mesh bags for later processing. All mussels were identified to species and returned to the stream. Spent valves were deposited in the University of Michigan Museum of Zoology's Mollusk Collection, but were not included in subsequent data analyses. Four sites (SK05, SK13, SK18 and SK22) were too deep to be surveyed using aquascopes, therefore SCUBA methods (in cooperation with the Michigan Natural Features Inventory, see Goforth et al., 2001) were used for data collection.

Timed search data were converted to catch per unit effort measures (CPUE) and expressed as the number of mussels $\mathrm{h}^{-1}$ of search. Approximate densities were calculated as the number of individuals per total area searched to facilitate species comparisons across sites (see Strayer, 1980). Density data were transformed to natural logarithms $(x+0.00001)$ prior to analysis. Intolerant mussel species (see Appendix I of Kopplin, 2002) were reported as the relative abundance of intolerant individuals (RAIU) in the total catch. Tolerant mussels were identified as those species common to silty, mucky or degraded habitat [i.e. Lampsilis siliquoidea (Barnes), Lasmigona complanata (Barnes), and Strophitus undulatus (Say), and those species that are habitat generalists (i.e. Amblema plicata (Say)) and P. grandis]. In total, six mussel species of the Raisin are intolerant, 10 are moderately tolerant, and five are tolerant. Species richness was defined as the number of living species at a site, and species diversity was calculated using the Shannon-Weaver Diversity Index:

$$
H^{\prime}=-\Sigma p_{i} \ln \left(p_{i}\right)
$$

where $p_{i}$ is the proportion of individuals in the $i$ th species and $\ln$ is the natural logarithm. Sites were grouped based on mussel species richness and diversity and these groupings were used in ANOVAs with habitat variables to detect significant trends.

\section{Habitat variables}

Reach-scale measures of habitat can be grouped into four categories: (i) visual habitat assessments calculated using rapid habitat assessment protocols; (ii) substratum; (iii) channel morphology, including channel shape, slope and sinuosity measures and (iv) other habitat variables (conductivity, percentage of reach in pools, riffles or glides, canopy cover, snags, discharge). A total of 84 habitat variables were estimated, many of which were correlated or redundant. Correlation matrices were used to reduce the variable set within each of the above categories, for subsequent use in a factor analysis. Based on inspection of the data, a correlation coefficient of 0.6 was selected as the criterion for forming groupings within each of the four categories; typically we selected one habitat variable to represent such a grouping of related measures. Non-linear variables were ln-transformed for subsequent analysis.

We performed a principal components analysis of the 22 remaining habitat variables to identify the common axes that describe habitat variability throughout the catchment. Axes were rotated using the orthogonal varimax rotation to help with interpretation (Norman \& Streiner, 1999), and metric loadings onto axes were examined to determine which habitat metrics best explained overall variation in habitat conditions amongst the 40 sites.

Visual habitat assessment employed two similar protocols to estimate overall habitat quality based on the sum of scores from multiple metrics. We used the index employed by the Michigan Department of Environmental Quality (hereafter referred to as DEQ) [see Michigan Department of Natural Resources (MDNR), 1991], as well as the US Environmental Protection Agency's Rapid Habitat Assessment for Low Gradient Streams (hereafter referred to as EPA) (see Barbour et al., 1999). Both indices rate the phys- 
ical habitat visually and reflect professional judgments of stream habitat condition in relation to the best possible conditions that could be expected of the particular stream reach in question. After data reduction, we retained four of the 21 visual assessment metrics for use in later analysis. These included epifaunal habitat (DEQ metric 1), which reflected substratum quality and overall instream habitat variability; flow stability (DEQ metric 4), bottom sedimentation (DEQ metric 5) and bank conditions (bank stability and riparian vegetation, DEQ metric 7). All visual habitat assessment variables used in subsequent analyses were normally distributed.

Substratum was assessed from a pebble count of 100 pebbles measured using a USGS gravelometer (US SAH-97, first described by Wolman, 1954). We estimated the diameter representing 16\% (D16), 50\% (D50) and $84 \%$ (D84) of the size distribution as commonly used measures of small, median and large particles (Gordon, McMahon \& Finlayson, 1992), and used the D84/D16 ratio as a measure of particle size variability. We also estimated particle size visually, and from thalweg scoops of substratum at three points along the transect we determined the per cent of the substratum $<2 \mathrm{~mm}$ diameter. Correlation analysis was used to reduce an initial set of 29 substratum variables to six for later analysis. 'Fines' corresponded to a combination of $<2$ and $2 \mathrm{~mm}$-sized particles, 'fine gravel' corresponded to 4-8 mm-sized particles, 'coarse gravel' was a combination of 8-16 mm-sized particles, 'cobble' corresponded to 16-180+ mm-sized particles and 'hardpan' was large slabs of very hard clay. This substratum classification scheme closely resembles the Wentworth Scale (see Allan, 1995), however 'pebbles' and 'cobbles' from the Wentworth Scale were condensed into a single category, 'cobbles', for this study. While 'fines' were negatively correlated with all other measures, and 'coarse gravel' and 'cobble' were marginally correlated $(r<0.4)$, these five variables were easily interpreted and used in future analysis. The D84/D16 ratio was included as a measure of variance in substratum particle size and, as it was not correlated to other measures, it was deemed a useful independent measure. All variables (except for 'fines' and 'fine gravel') were ln-transformed for subsequent analysis.

Channel morphology was determined from the average cross-sectional profile based on four transects within the 100-m reach. Each transect used at least seven measurement points reflecting significant channel features (e.g. bankfull location, toe of bank, thalweg, etc.), and a variety of channel shape descriptors then were calculated (Infante, 2001). A total of 22 related variables were reduced to seven by correlation analyses. We included a measure of channel fit (the ratio of bankfull to low-flow width), incision (the difference between bankfull and low-flow average depth), and low-flow hydraulic radius (the ratio of wetted area to wetted perimeter). We also included bankfull area, wetted perimeter, sinuosity and bank angles in the category of channel shape. Only the wetted perimeter and sinuosity variables needed to be ln-transformed prior to further analysis.

Additional habitat variables, including drainage area, channel units (pools, riffles and glides), canopy cover, snags, discharge and mean conductivity were examined for their potential role in explaining mussel distributions. Pools, riffles and glides were correlated with one another, but pools and glides were both kept for further analysis because they represent different habitats for mussels. We also retained snags, discharge and conductivity, based on expectations of their possible importance. All variables except pools and conductivity were $\ln$-transformed prior to further analysis.

\section{Catchment variables}

Subcatchment boundaries were delineated from 30-m resolution digital elevation maps (DEMs) (Seelbach \& Wiley, 1997) using ArcView [Environmental Systems Research Institute Inc. (ESRI), 2001], and subsequently used to calculate the drainage area of each site. In addition, local reach buffers $200 \mathrm{~m}$ in width $(100 \mathrm{~m}$ each side) extending $1 \mathrm{~km}$ upstream from the sample reach were delineated to allow estimation of land use in the riparian zone. We calculated the per cent compositions of geology and land use/cover within the subcatchment and within stream buffers. All percentage values were transformed as arcsine-square root prior to analysis. Surficial geology (Farrand \& Bell, 1984) was condensed into five categories for further analysis: (i) all moraines, (ii) outwash, (iii) clay lake plain, (iv) sand lake plain and (v) lakes. Land use/cover data were obtained from the Michigan Resource Information System and developed from $1: 24000$ maps and aerial photographs from 1979 to 1985, with an accuracy of approximately 1 ha (MDNR, 1990). Land use/cover classifications included seven 
categories: urban, agricultural, rangeland, forested, surface water, wetland or barren.

\section{Results}

\section{Mussel assemblage structure}

We collected 4667 individuals of 21 mussel species from 40 sites within the River Raisin. Pooling all collections, Fusconaia flava (Rafinesque) was the dominant species in the catchment, accounting for almost one-third of all individuals collected (Table 1). Other common species were A. plicata, L. siliquoidea,Elliptio dilatata (Rafinesque) and L. cardium; these four species combined accounted for an additional one-third of all individuals collected. The rarest species were Lasmigona costata (Rafinesque), Alasmidonta viridis (Rafinesque), Ptychobranchus fasciolaris (Rafinesque), Venustaconcha ellipsiformis (Conrad) and Leptodea fragilis (Rafinesque), each of which was represented by fewer than 20 individuals. The latter four species occurred as live individuals at four or fewer sites (Table 1). Lampsilis siliquoidea and S. undulatus were the most ubiquitous species, found at 26 and 23 sites respectively.

Significantly more individuals were collected in the upper basin than from the mid and lower portions of the basin (Fig. $2 \mathrm{a} ; F_{2,37}=3.8, P<0.05$ ). Over 275 individuals were collected, on average, from a $100 \mathrm{~m}$ reach in the upper basin, compared with 50-80 individuals per site in the middle and lower basins.

Species richness ranged from 0 to 12 per site (Table 1), with the greatest richness occurring in the upper mainstem of the River Raisin (sites SK08 and SK12). Species diversity, measured by the ShannonWeaver Index $\left(H^{\prime}\right)$, ranged from 0 to 0.89 among sites and decreased significantly from the upper to lower catchment (Fig. 2b; $F_{2,36}=4.2, \quad P<0.05$ ), as $\mathrm{did}$ species richness (Fig. 2c; $F_{2,37}=3.3, P<0.05$ ). Intolerant species were disproportionately represented in the upper basin compared with middle and lower regions of the basin (Fig. $2 d ; F_{2,37}=3.6, P<0.05$ ).

Because diversity and abundance of mussels varied widely among sites, we constructed four categories of sites based on the mussel assemblage, for later comparison with habitat variables. Sites with no living mussels were designated 'none'. 'Low' sites met at least two of the following criteria: (i) One to three species present; (ii) $0<H^{\prime} \leq 0.35$; (iii) $1-5$ individuals /species; or (iv) RAIU $=0$. 'Medium' sites met at least two of the following criteria: (i) four to eight species present; (ii) $0.35<H^{\prime} \leq 0.65$; (iii) $5-10$ individuals/species; or (iv) $0<\mathrm{RAIU} \leq 0.10$. 'High' sites met at least two of the following criteria: (i) more than eight species present; (ii) $H^{\prime}>0.65$; (iii) $>10$ individuals/species; or (iv) RAIU > 0.10. Based on the above criteria, nine sites fell into the 'high' category, 14 sites fell into the 'medium' category, 11 sites were in the 'low' category, and six sites fell into the 'none' category.

\section{Instream habitat and mussel distribution}

Overall habitat quality of stream reaches varied widely among sites, ranging from 74 to 169 (maximum score: 200) using EPA visual assessment metrics and from 46 to 119 (maximum score: 135) using DEQ metrics. The two rating systems were highly correlated ( $r=0.91, P<0.01, n=38)$, and the overall habitat assessment determined by each method was similar (Mann-Whitney $U$-test, $P>0.05$ ). Both methods identified the same site (SK12) as highest in quality; interestingly, this site is within a Nature Conservancy Preserve, and is one of the last remnants of land in the Raisin catchment with extensive forest, wetland and fen habitat surrounding the river. When an average habitat quality was estimated for sites associated with each of the four groupings based on mussel species richness and diversity metrics, sites with high mussel diversity were found to have higher habitat quality as well (Fig. $3 ; F_{3,34}=11.2, P<0.001$ ).

Bottom substratum, of potential importance to mussel distributions, varied markedly among sites based on median particle size. Just over one-third of the sites (13 of 38) had substratum consisting of fine sediments (Fig. 4a). Estimates of median particle size (D50) based on pebble counts substantiate this analysis. Sites grouped on the basis of mussel species richness and diversity demonstrated a consistent relationship with substratum (Fig. 4b). Sites with less fine substratum supported higher mussel diversity (Fig. $4 b ; F_{3,34}=3.3, P=0.05$ ).

When sites were grouped according to richness and diversity of the mussel assemblage, sites with higher flow stability supported higher mussel diversity (Fig. 5a; $F_{3,34}=16.8, P<0.001$ ). There also was a significant trend for higher quality mussel sites to 
*Presence/absence only is noted for Corbicula fluminea and Dreissena polymorpha. 


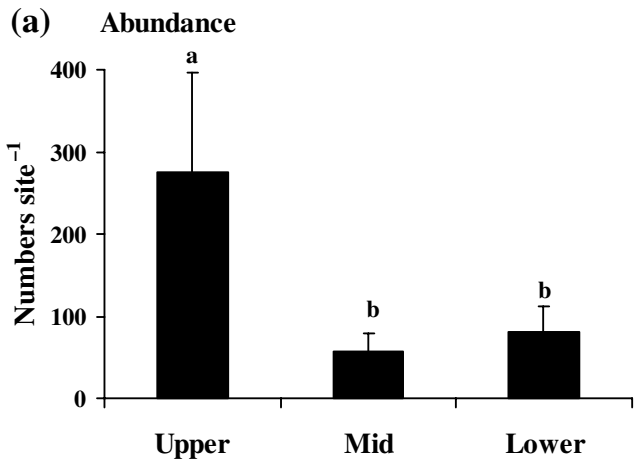

(b) Diversity
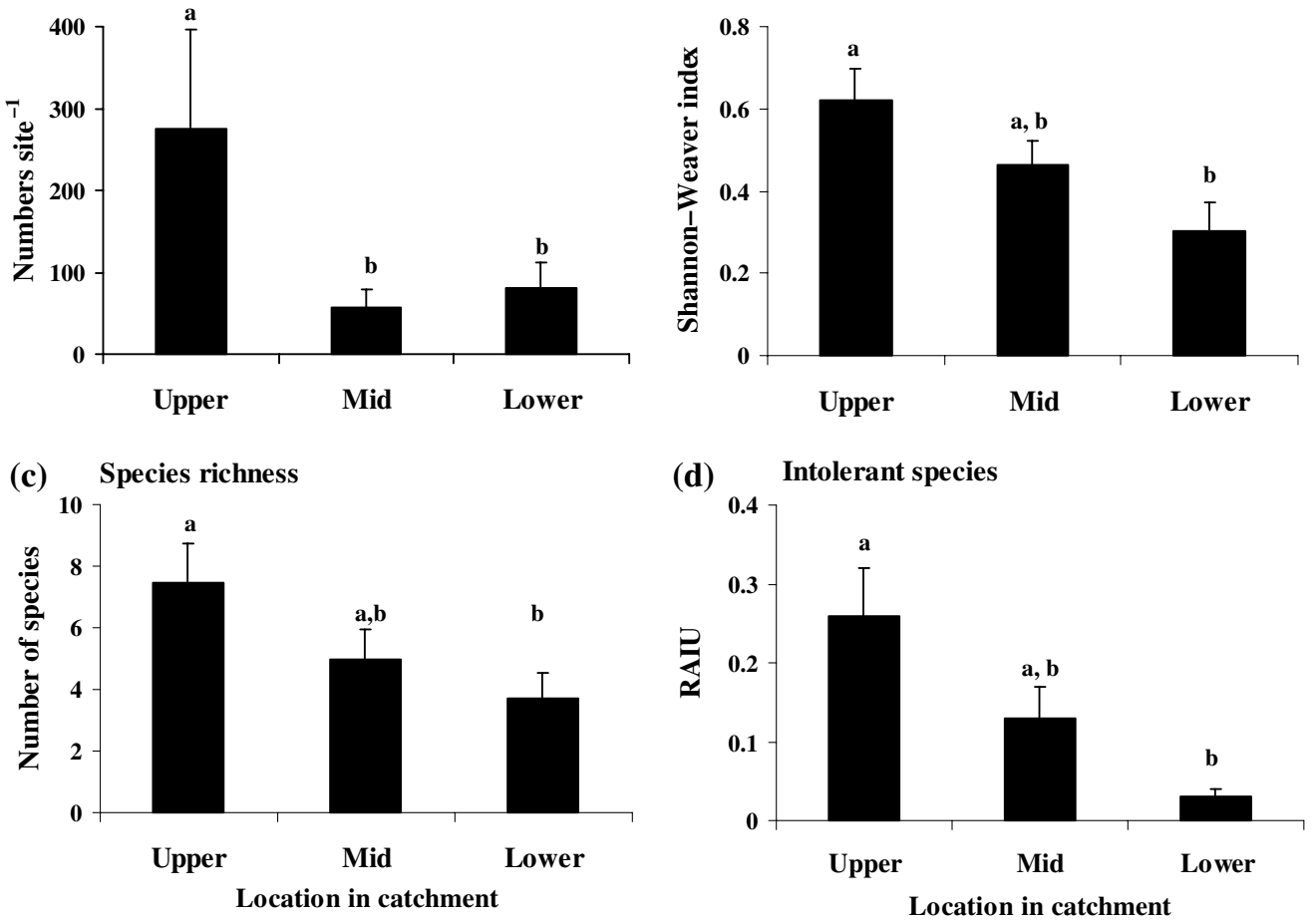

Fig. 2 Patterns of mussel abundance and diversity in the Raisin basin. (a) mussel abundance; (b) Shannon-Weaver species diversity; (c) species richness; (d) mean relative abundance of intolerant unionids (RAIU) as a percentage of total living species found at each site. Significantly different site groupings, based on Tukey's method for paired comparisons, are denoted by different letters, while groupings that share the same letter are not significantly different. One site (SK02) was removed from the upper catchment of (b) because it was an outlier. Error bars are $+1 \mathrm{SE}$.

have lower flow variability based on the difference between bankfull and wetted surface depth (Fig. 5b; $\left.F_{3,33}=3.78, P=0.05\right)$.

Conductivity, a measure of dissolved ions, is a useful descriptor of water chemistry at a site and one likely to indicate both ion availability and chemical

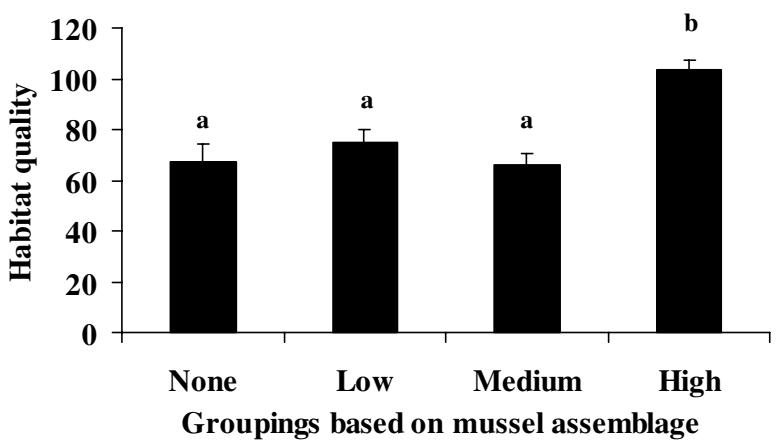

Fig. 3 Comparison of average habitat quality for four site groupings based on the mussel assemblage (see text for description of mussel groupings). Sites having excellent mussel communities had significantly higher habitat quality based on DEQ visual survey scores. Error bars are $+1 \mathrm{SE}$. pollution. We observed a significant difference between sites with high and low mussel diversity in relation to conductivity (Fig. $6 ; F_{3,34}=4.8, P<0.01$ ), which was higher at sites in the lower catchment.

\section{Site comparison of habitat variables by factor analysis}

Principal components analysis identified five components that together accounted for nearly $70 \%$ of the variation in habitat metrics among sites, indicating that discernible patterns in habitat conditions could be determined. The loadings of 14 of the 22 habitat measurements on each of the first five factors after orthogonal rotation (Table 2) suggest a reasonable interpretation for each axis. The first component can be interpreted as overall visual habitat quality, with emphasis on epifaunal substratum quality, flow stability and bank stability. Axis 2 represents channel shape and discharge, with emphasis on overall channel size, as specified by bankfull cross-sectional area. Also included is the wetted perimeter, an indication of 

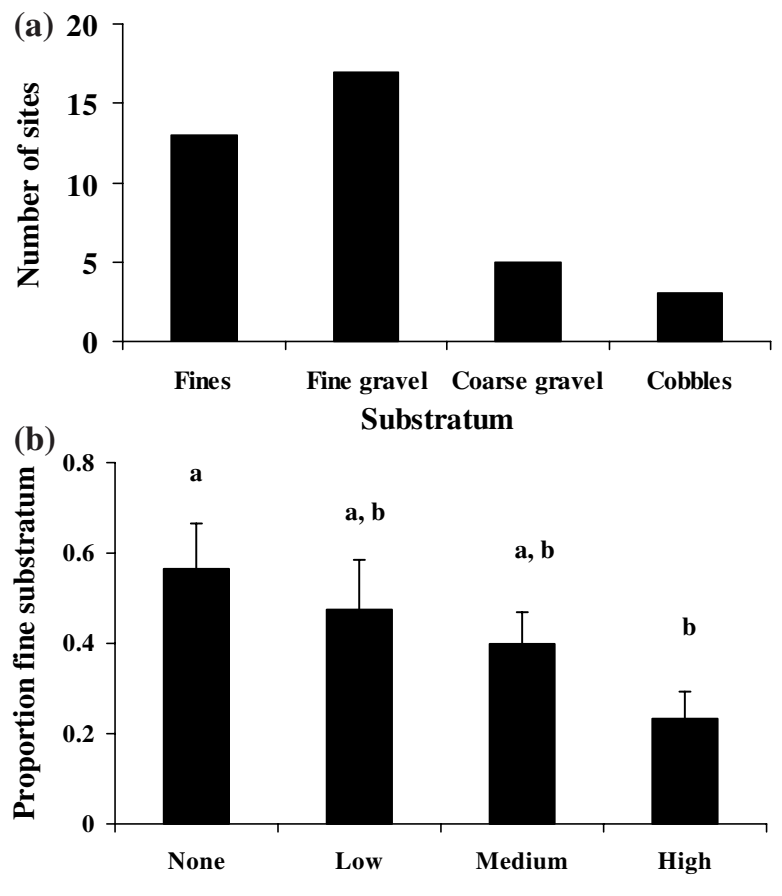

Groupings based on mussel assemblage

Fig. 4 Substratum characterisation across the Raisin basin and the response of the mussel assemblage to substratum. (a) Frequency distribution of substratum groupings across sites based on median particle size (D50); (b) Frequency distribution of mussel groupings across sites based on the proportion of reach bottom that is fine $(\leq 2 \mathrm{~mm})$ substratum. Significantly different groupings of mussel assemblages are denoted by different letters, while groupings that share the same letter are not significantly different. Error bars are $+1 \mathrm{SE}$.

overall habitat availability. The third axis is strongly determined by substratum measures, particularly coarse gravels and cobbles. The fourth axis is interpreted to represent channel structure and pattern, including sinuosity, channel fit and incision variables. The fifth component represents channel unit features, such as pools and glides. From this analysis, the same variables that explained variation in mussel assemblages also accounted for significant gradients in habitat conditions across the basin.

\section{Predictive modelling of mussel distribution and abundance}

Stepwise models for multiple linear and logistic regression provided an evaluation of the relative importance of reach and catchment-scale variables in predicting mussel assemblage diversity and the distribution of individual species. In total, eight different
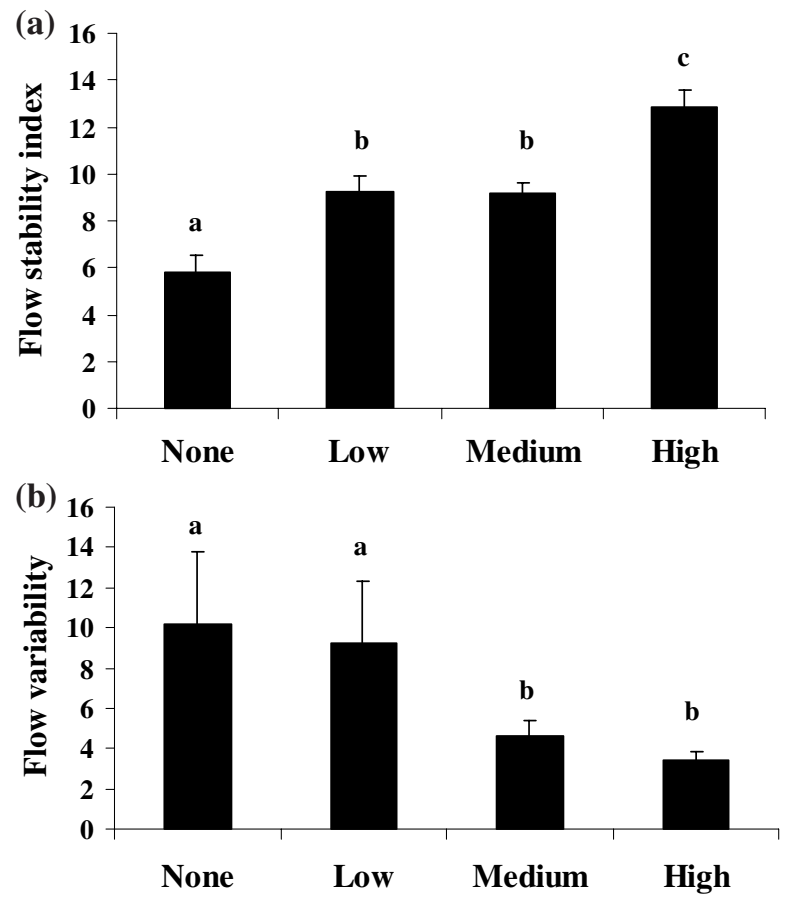

Groupings based on mussel assemblage

Fig. 5 Relation of mussel assemblage to (a) flow stability (DEQ metric 4) and (b) flow variability (bankfull depth - wetted depth). Significantly different groupings of mussel assemblages are denoted by different letters, while groupings that share the same letter are not significantly different. Error bars are $+1 \mathrm{SE}$.

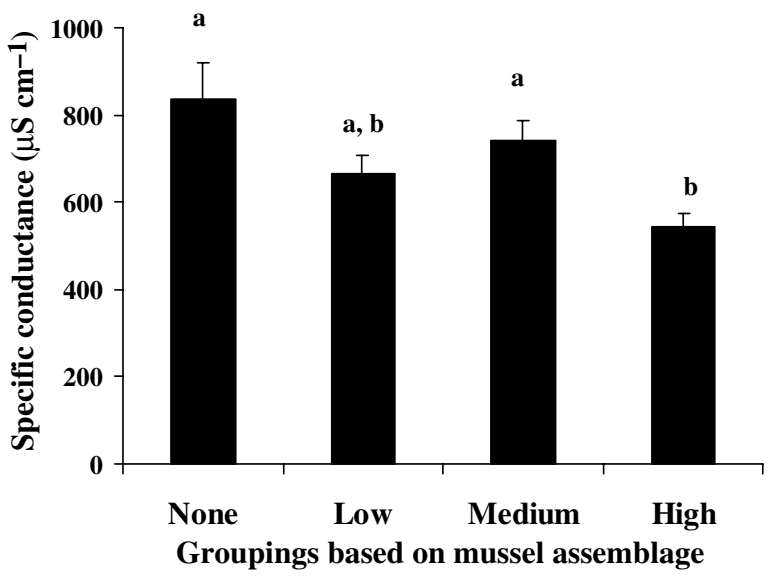

Fig. 6 The relationship between mussel communities and specific conductance. Significantly different groupings of mussel assemblages are denoted by different letters, while groupings that share the same letter are not significantly different. Error bars are +1 SE.

models were created from a subset of 22 habitat variables, four land-use variables and five geology variables from both the subcatchment and the local 
136 S.E. McRae et al.

Table 2 Principal components analysis identified five factors that together account for nearly $70 \%$ of the variation in habitat metrics among sites. DEQ and EPA total scores were omitted from this analysis because of their high correlation to the other visual habitat assessment metrics. Variables with loadings $>|0.70|$ are in bold

\begin{tabular}{|c|c|c|c|c|c|}
\hline & \multicolumn{5}{|c|}{ Component number } \\
\hline & 1 & 2 & 3 & 4 & 5 \\
\hline \multirow{3}{*}{$\begin{array}{l}\text { Eigenvalue } \\
\text { Variance explained (cumulative) }\end{array}$} & 4.47 & 3.66 & 3.49 & 2.10 & 1.59 \\
\hline & 20.3 & 36.9 & 52.8 & 62.3 & 69.5 \\
\hline & \multicolumn{5}{|c|}{ Factor pattern after varimax rotation } \\
\hline Epifaunal substratum (DEQ1) & 0.742 & 0.197 & 0.106 & 0.157 & 0.357 \\
\hline Flow stability (DEQ4) & 0.776 & 0.338 & 0.006 & -0.075 & -0.047 \\
\hline Sedimentation (DEQ5) & 0.465 & 0.470 & 0.339 & -0.039 & 0.076 \\
\hline Bank stability (DEQ7) & 0.731 & -0.208 & 0.102 & -0.213 & -0.024 \\
\hline Snags & 0.376 & -0.062 & -0.071 & -0.016 & 0.297 \\
\hline Pools & 0.093 & -0.100 & -0.261 & 0.080 & 0.873 \\
\hline Glides & 0.083 & 0.091 & -0.038 & 0.060 & -0.903 \\
\hline Fines & -0.141 & -0.164 & -0.647 & 0.020 & 0.128 \\
\hline Fine gravel & 0.037 & -0.245 & 0.091 & 0.110 & 0.061 \\
\hline Coarse gravel & 0.185 & -0.115 & 0.781 & 0.041 & 0.014 \\
\hline Cobble & 0.060 & 0.049 & 0.865 & 0.107 & -0.227 \\
\hline Hardpan & -0.317 & 0.595 & 0.372 & -0.310 & -0.148 \\
\hline D84/D16 & -0.179 & 0.208 & 0.761 & -0.098 & 0.054 \\
\hline Bankfull area & -0.021 & 0.835 & -0.006 & 0.478 & -0.040 \\
\hline Incision & -0.326 & 0.048 & -0.222 & 0.740 & -0.098 \\
\hline Channel fit & -0.231 & 0.159 & 0.071 & 0.843 & 0.222 \\
\hline Wetted surface perimeter & 0.115 & 0.935 & 0.121 & 0.063 & -0.053 \\
\hline Low flow hydraulic radius & 0.604 & 0.128 & -0.171 & -0.011 & -0.050 \\
\hline Sinuosity & 0.218 & 0.019 & 0.179 & 0.731 & -0.150 \\
\hline Discharge & 0.420 & 0.798 & -0.133 & 0.105 & -0.124 \\
\hline Conductivity & -0.573 & 0.020 & -0.059 & 0.339 & 0.312 \\
\hline Bank angle & -0.429 & -0.461 & -0.369 & 0.198 & 0.008 \\
\hline
\end{tabular}

Table 3 Multiple linear and logistic (Amblema plicata only) regression models for total mussels, the five most common species (F. flava, A. plicata, E. dilatata and L. cardium) and five most widespread species (S. undulatus, L. siliquoidea, F. flava, P. grandis and E. dilatata) in the River Raisin catchment. ' + ' and ' - ' indicate a positive or negative relationship with the dependent variable. Unless indicated as local, all land cover and geology variables entering the models were at the subcatchment scale

\begin{tabular}{|c|c|c|c|c|c|}
\hline \multirow{2}{*}{$\begin{array}{l}\text { Dependent } \\
\text { variable }\end{array}$} & \multirow{2}{*}{$\begin{array}{l}R^{2} \\
(P<0.01)\end{array}$} & \multicolumn{4}{|l|}{ Independent variables } \\
\hline & & First & Second & Third & Fourth \\
\hline Total mussels & 0.63 & Flow stability $(+)$ & EPA total $(+)$ & Fine gravels $(+)$ & Moraine, local (+) \\
\hline Fusconaia flava & 0.54 & Flow stability $(+)$ & Fine gravels $(+)$ & Incision $(-)$ & - \\
\hline Amblema plicata* & 0.51 & Glides (+) & Lakeplain sands (+) & Lakeplain clay $(+)$ & Fines $(+)$ \\
\hline Lampsilis siliquoidea & 0.51 & Moraine (+) & Fines $(+)$ & Bank angle (-) & Forest, local (-) \\
\hline Elliptio dilatata & 0.75 & Epifaunal habitat $(+)$ & Channel fit (+) & Moraine (+) & Outwash, local (+) \\
\hline Lampsilis cardium & 0.86 & Flow stability $(+)$ & DEQ total $(+)$ & Lakes $(+)$ & Outwash $(+)$ \\
\hline Strophitus undulatus & 0.62 & Flow stability $(+)$ & Fines $(-)$ & Bank angle (-) & Lakeplain clay (-) \\
\hline Pyganodon grandis & 0.78 & Epifaunal habitat $(+)$ & Discharge (-) & Lakeplain clay (+) & - \\
\hline
\end{tabular}

${ }^{*}$ Logistic regression model.

reach (Table 3). Total mussel abundance throughout the catchment was best predicted by a model $\left(R^{2}=0.63, P<0.001\right)$ that included flow stability, overall habitat quality as indicated by EPA total score, the percentage of fine gravel in the reach substratum, and the percentage of moraine in the local reach. Regression models developed for the most common and most widespread species included a wide variety of measures, resulting in a different model for each species (Table 3). However, the models exhibited 
some notable similarities. Visual habitat assessment metrics were included for all but two species $(A$. plicata and $L$. siliquoidea), geology variables were included for all but one species ( $F$. flava), and over half of the models included substratum measures.

\section{Discussion}

Despite the presumed accumulation of threats to the river, the River Raisin has maintained a relatively diverse freshwater mussel community over the past century. While surveys from the early to mid-20th century reported 27 mussel species, 21 species are still known to occur in the catchment, and several of these species have abundant, naturally reproducing populations. Temporal comparisons suggest that two species (L. complanata and S. undulatus) have made significant range expansions; however, five species (A. viridis, A. plicata, Cyclonaias tuberculata, Villosa fabalis and $V$. iris) have experienced a significant decline in their range throughout the Raisin.

Present-day mussel biodiversity shows a clear spatial pattern, with much higher abundance and diversity of mussels in the upper and middle portions of the basin compared with the lower basin. Although most previous studies of microhabitat have not found strong predictive relationships with mussel distributions, this study revealed significant associations between key habitat variables and overall mussel abundance and richness. Reach-scale measures of visually assessed habitat quality, flow stability, substratum and conductivity differed amongst sites grouped by mussel diversity. These reach-scale measures also were frequently incorporated into regression models that were developed to predict the pattern of the total mussel assemblage as well as individual species. Of the catchment-scale variables examined, measures of surficial geology at the scale of the subcatchment typically were included in predictive models, and land cover/ use estimated for riparian buffers was included for some, but not all, species. Collectively these results suggest that the pattern of mussel distribution throughout this catchment is influenced by a combination of reach and larger scale variables.

\section{Spatial pattern of the mussel community}

The abundance, richness and diversity of mussels differed between the upper and lower Raisin catch- ment, suggesting that habitat conditions are more favourable, environmental stresses fewer, or both, in the upper and middle reaches compared with the lower reaches. Prior studies of the Raisin River found similar trends. Indices of fish assemblages and instream habitat were consistently higher in tributaries of the upper catchment in a study by Roth et al. (1996). Using similar divisions of the upper, middle and lower Raisin catchment, Schroeder (1994) found invertebrate metrics to be higher in the upper and middle regions. Nutrient concentrations increased along the river's length, and were greatest in the lower catchment, where the ratio of agricultural to forested land was also higher (Castillo, Allan \& Brunzell, 2000). Thus, the spatial pattern of mussels in this catchment probably reflects the distribution of critical habitats and locations where human impacts are less evident.

The significant association of mussel assemblages with a number of habitat variables, and the spatial gradient in mussel diversity from the upper to the lower basin, suggests that the mussel fauna and environmental characteristics probably show some degree of spatial autocorrelation. Vaughn \& Taylor (2000) document the spatial dependence of mussels, host fish and local and landscape environmental characteristics in the Red River network in south central U.S.A. They attribute this spatial pattern to non-random patterns of dispersal, physical attributes of the surrounding landscape that influence stream morphology, water chemistry and local habitat characteristics, and historical constraints that determine the regional species pool. We examined spatial autocorrelation by mapping mussel diversity, habitat quality, substratum quality and conductivity to assess visually how these four measures covaried throughout the catchment (Fig. 7). The upstream to downstream trend is clear, although considerable variability is evident in all four measures throughout the catchment. A correlation analysis (Kopplin, 2002), that used distance from the river mouth and many environmental variables, found spatial location of the sites to be correlated to three visual habitat quality metrics and two channel shape measures. Visual assessment of epifaunal substratum $(r=0.53)$, flow stability $(r=0.54)$ and bank conditions $(r=0.48)$ were positively associated with site position, and incision $(r=-0.42)$ and channel fit $(r=-0.43)$ were negatively associated, indicating that some important 


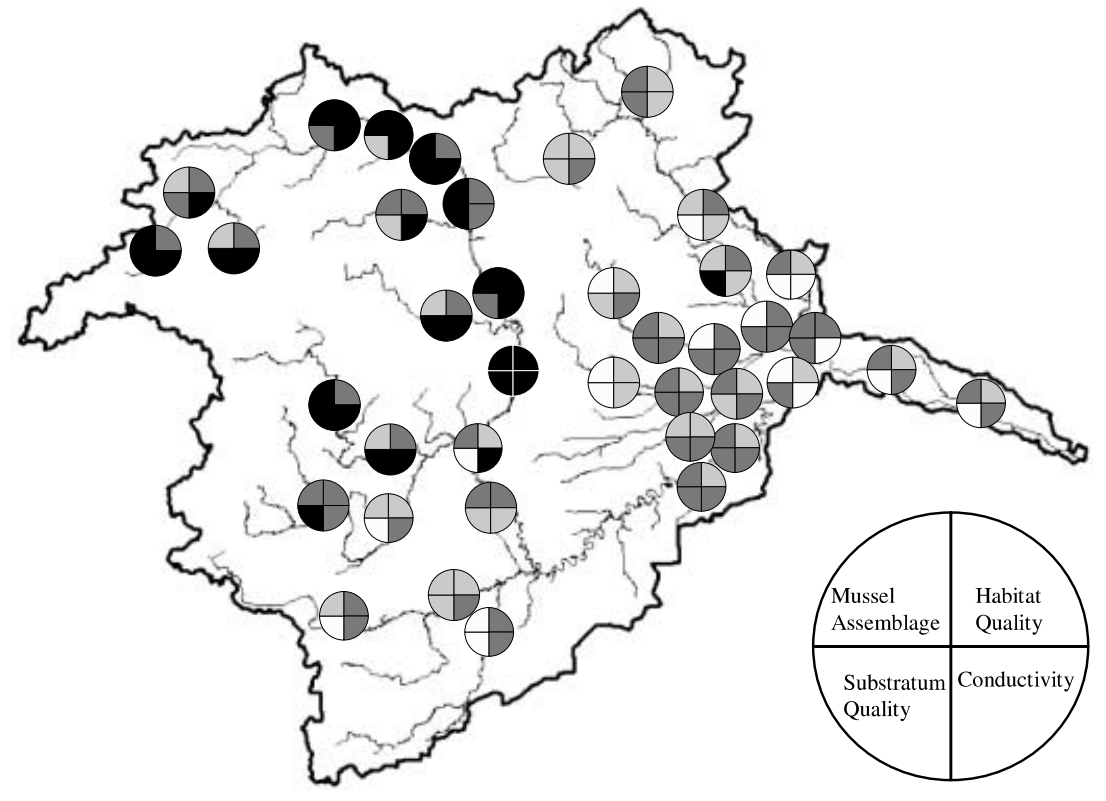

Fig. 7 Spatial relationships among the mussel assemblage, habitat quality, substratum quality and conductivity. Black $=$ very good, dark grey $=$ good, light grey $=$ fair, white $=$ poor, based on quartiles of data range. Highest values were considered excellent except for conductivity, where low values were assumed to indicate best conditions. variables showed an overall spatial trend. It seems therefore that spatial autocorrelation is important; however, the demonstrated relationships between mussel diversity and in-stream habitat features are not solely explained by spatial pattern, as indicated by the variation in scores depicted in Fig. 7.

\section{Mussel distributions and environmental variables}

Prior studies attempting to elucidate the fine-scale habitat variables that predict the distribution of mussel species have been mostly unsuccessful (Strayer, 1981; Holland-Bartels, 1990; Strayer \& Ralley, 1993). While such variables as sediment grain size, current speed, water depth and distance from shore have intuitive appeal (Strayer, 1999), quantitative studies (Tevesz \& McCall, 1979; Strayer, 1981; Holland-Bartels, 1990; Strayer \& Ralley, 1993; Layzer \& Madison, 1995) have found only weak links between simple microhabitat descriptors and mussel distribution. In some regions, unionid distribution on a scale of 1-10 km is fairly well described by stream size and catchment characteristics (van der Schalie, 1938; Strayer, 1983, 1993), suggesting that environmental conditions measured at a larger spatial scale might be more useful. However, some attempts to characterise the microhabitat conditions (i.e. $0.1-10 \mathrm{~m}$ scale) that might explain mussel distributions have been successful. In an Ontario river, Salmon \& Green (1983) reported significant differences in microhabitat attri- butes between areas with mussels and those without, and among areas occupied by different species of mussels; however, the strength of such microhabitat associations was not reported. They found that mussels occurred most frequently in shallow, slow current, and more vegetated areas, but with a preference for coarser substrata if they occur within tolerable depth and current regimes. Layzer \& Madison (1995) found that mussels in a small stream in Kentucky lived mostly in reaches with low shear stress and that water depth and velocity were important factors limiting the distribution of mussels during base flow. In addition, Strayer (1999) found that small-scale predictors can be very useful. In the present study, both reach scale (10-100 m) and catchment scale (1-100 km) factors were found to influence mussel distributions.

Visual estimation of habitat quality at the reach scale, a measure not previously reported for mussel surveys, seems to be a very good indicator of the quality of the habitat for mussels in the River Raisin. Mussel assemblage attributes were correlated with several visually assessed metrics as well as overall habitat quality (Fig. 3). This finding is important because rapid habitat assessments are quick and easy to perform, and therefore can potentially be used in future studies to assess suitable conditions for mussel populations.

For burrowing and filter-feeding mussels, substratum quality is an important factor determining their 
survival in the streambed. Several studies have alluded to substratum type influencing the abundance and local distribution of many unionid species but have not found significant statistical relationships between substratum and mussels (Harman, 1972; Gorman \& Karr, 1978; Salmon \& Green, 1983; Lewis \& Riebel, 1984; Layzer \& Madison, 1995). While some species appear to be substratum-specific, most tolerate a fairly wide range of stream bottom types (Tevesz \& McCall, 1979; Strayer, 1981; Salmon \& Green, 1983), and this may account for studies that question the causal role of the substratum in the distribution of freshwater mussels (Lewis \& Riebel, 1984; HollandBartels, 1990; Strayer \& Ralley, 1993; Strayer, 1999). Despite this generality, in the current study we found significant relationships between the substratum and mussels, several species were correlated with different size classes of gravel, and in general more mussels were found in fine gravel than on other substrata.

Hydrologic variability can have a marked effect on the distribution and abundance of invertebrate and fish populations in rivers (Poff et al., 1997). Di Maio \& Corkum (1995) found distinctive mussel communities based on the hydrological variability of rivers in Ontario and Michigan, and Strayer (1993) reported that some mussel species occurred more consistently in hydrologically stable than in hydrologically flashy streams in New York. Scouring of individual mussels and burial by sediment are possible adverse effects of a river flow that is too variable, which may account for Strayer's (1999) finding that mussel beds were spatially coincident with flow refuges in two small rivers in south-eastern New York. The River Raisin was classified as 'event-responsive and variable' in comparison with other systems in the northern, central and western basin of Lake Erie (Richards, 1990), but is relatively more stable and groundwater-influenced in its upper and middle regions, which are dominated by glacial till and moraines. Thus the association of richer mussel assemblages with flow stability (Fig. 5) and the upper catchment is consistent with expectations of the importance of hydrologic variability and its linkage to substratum stability.

In comparison with reach-scale variables, which demonstrated a number of significant relationships with mussel distributions, only surficial geology was consistently important amongst the catchment variables. The scarcity of significant correlations between mussel community measures and land cover/use is surprising because a substantial body of literature documents the effects of land use on stream communities (Schlosser, 1991; Richards et al., 1996; Roth et al., 1996; Allan et al., 1997; Wang et al., 1997, 2001). In this study the amount of wetland and urban development in the local buffer accounted for a small percentage of the variation in overall mussel density and diversity throughout the catchment.

The absence of strong correlations between land use and mussel distributions may be because geology, which also influences land cover/use, is the overriding catchment-level variable. Spatial patterns in the underlying geology influence hydrology through control of groundwater versus surface water contributions, and probably account for greater flow stability in the upper and middle catchment. Surficial geology also governs substratum through its influence on parent material, slope and current velocity, and helps to determine the chemistry and turbidity of a river. Although low alkalinity or high salinity can restrict mussel distributions, Strayer (1983), in an earlier study of the mussel fauna of the River Raisin, argued that these variables are probably not important to the mussel fauna of this catchment. Thus our finding of an association with conductivity may be a spurious reflection of an upstream-downstream faunal gradient, and a downstream increase in conductivity because of natural and anthropogenic causes. In sum, while the absence of demonstrated relationships of mussel distributions with land cover/use is somewhat surprising, our finding of a strong influence of subcatchment scale geology corroborates Strayer's (1983) suggestion that surface geology is an important factor in the ecology of freshwater mussels. Indeed, the broad spatial patterns documented in Fig. 7 may all trace their origins to underlying relationships with geological pattern.

\section{Acknowledgments}

Reuben Goforth provided valuable feedback on the original thesis publication. David Strayer and an anonymous reviewer provided helpful reviews of the original manuscript. The assistance of Rina Rossi, Jennifer Opdyke (Jo) Wilhelm, Janelle Francis, David Stagliano, Pete Badra, Stephanie Carman, Sara Creque, Brian McRae, Martha Carlson, Rebecca Cifaldi, Rosie Clarke, Bethany Soule, Karla Clark, Renee Sherman-Mulcrone, Dana Infante and Mike Moeller 
in data collection and analysis was invaluable. Chris Geddes, Rebecca Cifaldi, Geoffrey Duh, Diana Karwan and Paul Richards provided GIS consulting and analysis. Support for this project came from several sources: The Doris Duke Charitable Foundation, the Michigan Department of Natural Resources Natural Heritage Grant Program, The Nature Conservancy's Small Grant Program, discretionary funds from the Rackham Graduate School at the University of Michigan, and the Water and Watersheds Program (NSF EAR 99-00679).

\section{References}

Allan J.D. (1995) Stream Ecology: Structure and Function of Running Waters. Kluwer Academic Publishers, Dordrecht, The Netherlands. 388 pp.

Allan J.D., Erickson D.L. \& Fay J. (1997) The influence of catchment land use on stream integrity across multiple spatial scales. Freshwater Biology, 37, 149-161.

Arbuckle K.E. \& Downing J.A. (2002) Freshwater mussel abundance and species richness: GIS relationships with watershed land use and geology. Canadian Journal of Fisheries and Aquatic Sciences, 59, 310-316.

Barbour M.T., Gerritsen J., Snyder B.D. \& Stribling J.B. (1999) Rapid Bioassessment Protocols for Use in Streams and Wadeable Rivers: Periphyton, Benthic Macroinvertebrates and Fish, 2nd edn. EPA 841-B-99-002. U.S. Environmental Protection Agency, Office of Water, Washington, D.C.

Castillo M.M., Allan J.D. \& Brunzell S. (2000) Nutrient concentrations and discharges in a Midwestern agricultural catchment. Journal of Environmental Quality, 29, 1142-1151.

Cifaldi R.L., Allan J.D., Duh J.D. \& Brown D.G. Spatial patterns in land cover of exurbanizing watersheds of south-eastern Michigan. Landscape and Urban Planning, in press.

Di Maio J. \& Corkum L.D. (1995) Relationship between the spatial distribution of freshwater mussels (Bivalvia: Unionidae) and the hydrological variability of rivers. Canadian Journal of Zoology, 73, 663-671.

Environmental Systems Research Institute Inc. (ESRI) (2001) ArcView 8.1 for Windows. Redlands, CA.

Farrand W.R. \& Bell D.L. (1984) Quaternary Geology of Southern Michigan. University of Michigan, Ann Arbor, MI.

Fuller S.L.H. (1974) Clams and mussels (Mollusca: Bivalvia). In: Pollution Ecology of Freshwater Invertebrates (Eds C.W. Hart \& S.L. Fuller), pp. 215-273. Academic Press, New York.
Goforth R.R., Stagliano D., Cohen J., Penskar M., Lee Y.M. \& Cooper J. (2001) Biodiversity Analysis of Selected Riparian Ecosystems within a Fragmented Landscape. Report No. 2001-06. Michigan Natural Features Inventory, Lansing, MI.

Gordon N.D., McMahon T.A. \& Finlayson B.L. (1992) Stream Hydrology: an Introduction for Ecologists. John Wiley, Chinchester.

Gorman O.T. \& Karr J.R. (1978) Habitat structure and stream fish communities. Ecology, 59, 507-515.

Harding J.S., Benfield E.F., Bolstad P.V., Helfman G.S. \& Jones III E.B.D. (1998) Stream biodiversity: the ghost of land use past. Proceedings of the National Academy of Science, 95, 14843-14847.

Harman W.N. (1972) Benthic substrates: their effect on fresh-water mollusca. Ecology, 53, 271-277.

Holland-Bartels L.E. (1990) Physical factors and their influences on the mussel fauna of a main channel border habitat of the upper Mississippi River. Journal of the North American Benthological Society, 9, 327-335.

Infante D.M. (2001) The effects of channel shape on fish assemblage structure. M.S. thesis, University of Michigan, Ann Arbor, MI.

Knutilla R.L. \& Allen W.B. (1975) Water resources of the River Raisin basin, southeastern Michigan. United States Geological Survey Hydrologic Investigations Atlas HA-520.

Kopplin S.E. (2002) Environmental, geologic and anthropogenic determinants of freshwater mussel (Bivalvia: Unionidae) distribution in an agricultural watershed in southeastern Michigan. M.S. thesis, University of Michigan, Ann Arbor, MI.

Kovalak W.P., Dennis S.D. \& Bates J.M. (1986) Sampling effort required to find rare species of freshwater mussels. In: Rationale for Sampling and Interpretation of Ecological Data in the Assessment of Freshwater Ecosytems (Ed. B.G. Isom), pp. 34-45. ASTM STP 894. American Society for Testing and Materials, Philadelphia, PA.

Layzer J.B. \& Madison L.M. (1995) Microhabitat use by freshwater mussels and recommendations for determining their instream flow needs. Regulated Rivers: Research and Management, 10, 329-345.

Lewis J.B. \& Riebel P.N. (1984) The effect of substrate on burrowing freshwater mussels (Unionidae). Canadian Journal of Zoology, 62, 2023-2025.

McMahon R.F. (1991) Mollusca: Bivalvia. In: Ecology and Classification of North American Freshwater Invertebrates (Eds J.H. Thorp \& A.P. Covich), pp. 315-399. Academic Press, San Diego, California.

Michigan Department of Natural Resources (MDNR) (1990) Current Use Inventory: Data Collection Procedures and Definitions. Michigan Resources Inventory Program, Michigan DNR, Land and Water Management Division. 
Michigan Department of Natural Resources (MDNR) (1991) Qualitative Biological and Habitat Survey Protocols for Wadable Streams and Rivers. GLEAS procedure No. 51. Michigan DNR, Surface Water Quality Division, Great Lakes Environmental Assessment Section.

Norman G.R. \& Streiner D.L. (1999) PDQ Statistics, 2nd edn. B.C. Decker, Inc. Hamilton, Ontario, Canada. 188 pp.

Omernik J.M. (1987) Ecoregions of the conterminous United States. Annals of the Association of American Geographers, 77, 118-125.

Poff N.L., Allan J.D., Bain M.B., Karr J.R., Prestegaard K.L., Richter B.D., Sparks R.E. \& Stromberg J. C. (1997) The natural flow regime: a paradigm for river conservation and restoration. BioScience, 47, 769-784.

Richards R.P. (1990) Measures of flow variability and a new flow-based classification of Great Lakes tributaries. Journal of Great Lakes Research, 16, 53-70.

Richards C., Johnson L.B. \& Host G.E. (1996) Landscapescale influences on stream habitats and biota. Canadian Journal of Aquatic Sciences, 53 (Suppl. 1), 295-311.

Roth N.E., Allan J.D. \& Erickson D.L. (1996) Landscape influences on stream biotic integrity assessed at multiple spatial scales. Landscape Ecology, 11, 141-156.

Salmon A. \& Green R.H. (1983) Environmental determinants of unionid clam distribution in the Middle Thames River, Ontario. Canadian Journal of Zoology, 61, 832-838.

van der Schalie H. (1938) The naiad fauna of the Huron River, in southeastern Michigan. University of Michigan Museum of Zoology Miscellaneous Publication, 40, 1-83.

van der Schalie H. (1945) The value of mussel distribution in tracing stream confluence. Papers of the Michigan Academy of Science, Arts, and Letters, 30, 355-373.

van der Schalie H. \& van der Schalie A. (1950) The mussels of the Mississippi River. American Midland Naturalist, 44, 448-466.

Schlosser I.J. (1991) Stream fish ecology: a landscape perspective. BioScience, 41, 704-712.

Schroeder K.L. (1994) The distribution of macroinvertebrates in an agricultural watershed: the influence of instream habitat. M.S. thesis, University of Michigan, Ann Arbor, MI.

Seelbach P.W. \& Wiley M.J. (1997) Overview of the Michigan Rivers Inventory (MRI) Project. State of Michigan Department of Natural Resources Fisheries Division Technical Report Number 97-3. 33 pp.

Smith G.R., Taylor J.N. \& Grimshaw T.W. (1981) Ecological survey of fishes in the Raisin River drainage, Michigan. Michigan Academician, Papers of the Michigan Academy of Science, Arts and Letters, 13, 275-305.
Stansbery D.H. (1970) Eastern freshwater mollusks (I) The Mississippi and St. Lawrence River systems. Malacologia, 10, 9-22.

Strayer D. (1979) Some recent collections of mussels from southeastern Michigan. Malacological Review, 12, 93-95.

Strayer D. (1980) The freshwater mussels (Bivalvia: Unionidae) of the Clinton River, Michigan, with comments on man's impact on the fauna, 1870-1978. The Nautilus, 94, 142-149.

Strayer D. (1981) Notes on the microhabitat of unionid mussels in some Michigan streams. American Midland Naturalist, 106, 411-415.

Strayer D. (1983) The effects of surface geology and stream size on freshwater mussel (Bivalvia, Unionidae) distribution in southeastern Michigan, U.S.A. Freshwater Biology, 13, 253-264.

Strayer D. (1993) Macrohabitats of freshwater mussels (Bivalvia: Unionacea) in streams of the northern Atlantic Slope. Journal of the North American Benthological Society, 12, 236-246.

Strayer D. (1999) Use of flow refuges by unionid mussels in rivers. Journal of the North American Benthological Society, 18, 468-476.

Strayer D. \& Ralley J. (1993) Microhabitat use by an assemblage of stream-dwelling unionaceans (Bivalvia), including two rare species of Alasmidonta. Journal of the North American Benthological Society, 12, 247-258.

Strayer D.L., Claypool S. \& Sprague S.J. (1997) Assessing unionid populations with quadrats and timed searches. In: Conservation and management of freshwater mussels II: initiatives for the future (Eds K.S. Cummings, A.C. Buchanan, C.A. Mayer \& T.J. Naimo), pp. 163168. Proceedings of a UMRCC symposium, 16-18 October 1995, St Louis, Missouri. Upper Mississippi River Conservation Committee, Rock Island, Illinois.

Tevesz M.J.S. \& McCall P.L. (1979) Evolution of substratum preference in bivalves (Mollusca). Journal of Paleontology, 53, 112-120.

Turgeon D.D., Quinn J.F. Jr., Bogan A.E., Coan E.V., Hochberg F.G., Lyons W.G., Mikkelsen P., Neves R.J., Roper C.F.E., Rosenberg G., Roth B., Scheltema A., Sweeney M.J., Thompson F.G., Vecchione M. \& Williams J.D. (1988) Common and scientific names of aquatic invertebrates from the United States and Canada: Mollusks. American Fisheries Society Special Publication 26, Bethesda, MD. Second Edition, 536 pp.

Vaughn C.C. (1997) Regional patterns of mussel species distributions in North American rivers. Ecography, 20, 107-115.

Vaughn C.C. \& Taylor C.M. (2000) Macroecology of a host-parasite relationship. Ecography, 23, 11-20. 
142 S.E. McRae et al.

Wang L., Lyons J., Kanehl P. \& Gatti R. (1997) Influences of watershed land use on habitat quality and biotic integrity in Wisconsin streams. Fisheries, 22, 6-12.

Wang L., Lyons J., Kaenhl P. \& Bannerman R. (2001) Impacts of urbanization on stream habitat and fish across multiple spatial scales. Environmental Management, 28, 255-266.
Wolman M.G. (1954) A new method of sampling coarse riverbed. Transactions of the American Geophysical Union, 35, 951-956.

(Manuscript accepted 20 October 2003) 